\title{
Flood risk analysis: uncertainties and validation
}

\author{
Hochwasserrisikoanalysen: Unsicherheiten und Validierung
}

von B. Merz, H. Kreibich, H. Apel

\section{Kurzfassung/Summary}

Zur Quantifizierung des Hochwasserrisikos werden Risikoanalysen durchgeführt. Solche Analysen beschäftigen sich typischerweise mit extremen Ereignissen und Versagensszenarios, die zum Zeitpunkt der Analyse kaum oder überhaupt nicht beobachtet wurden. Aus diesem Grund sind Risikoanalysen mit beträchtlicher Unsicherheit verbunden. Analysen zur Unsicherheit von Hochwasser-Risikoaussagen werden heute immer noch selten durchgeführt. Dieser Beitrag argumentiert für die Durchführung von Unsicherheitsanalysen und zeigt, dass diese (1) Risikoanalysen verbessern, (2) die Validierung bzw. Plausibilisierung von Risikoanalysen unterstützen, und (3) eine zusätzliche Information für die Entscheidungsfindung sind.

The aim of flood risk analyses is to quantitatively assess the flood risk. In its broad sense, flood risk is defined as the probability of adverse consequences due to inundation. Flood risk analyses are typically dealing with extreme events and failure scenarios which have hardly been (or not at all) observed. Therefore, flood risk assessments are accompanied with considerable uncertainty. Today, it is not standard practice to explicitly analyse the uncertainty bounds of flood risk estimates. This paper discusses the value of uncertainty analysis for flood risk analysis. We argue in favour of uncertainty analyses in flood risk assessments, since uncertainty considerations (1) improve risk analyses, (2) help to confirm or falsify risk analyses, and (3) support decision-making.

\section{Introduction}

Decisions on flood mitigation and risk management are usually based on flood risk assessments. Such assessments may be associated with significant uncertainty (e.g. Apel et al., 2004, 2006, Merz et al., 2004, Downton et al., 2005). Although uncertainty analysis has received increased attention in hydrology and risk analysis during the last years, it is still not standard practice. In flood risk analysis, explicit quantification of uncertainty is the exception, rather than the rule. Pappenberger and Beven (2006) discuss seven arguments that are frequently raised against the use of uncertainty analysis in hydrological and hydraulic modelling, and advance the view that these arguments are not tenable. Similarly, we emphasise the value of uncertainty considerations in flood risk analysis. We argue that uncertainty considerations (1) improve flood risk analyses, (2) help to confirm or falsify risk analyses, and (3) support decision-making for flood risk mitigation. In the following, we use a broad definition of the term risk. We define flood risk as the probability of adverse consequences due to inundation. Therefore, risk encompasses flood hazard (i.e. flood discharges and associated probability) and flood damages.

\section{Uncertainty considerations improve flood risk analysis}

The quantification of the flood risk of a certain area is a process where many decisions have to be made. The spectrum of possibilities to model the flood risk chain "triggering weather event - runoff generation in the basin - flood routing - behavior of flood defense systems - inundation - damage" is wide, from complex approaches involving numerical simulation models (e.g., Dutta et al., 2003) to simplified approaches, such as the combination of flood frequency analysis with loss estimation (e.g., Merz et al., 2002). The risk analyst has to decide on the overall risk analysis approach, on the processes that are included, on the representation of the processes by models, and on the model parameterization, including the level of detail and boundary conditions. For most choices no clear-cut answers can be given, however, these choices influence the estimation of the flood risk. Further, the overall uncertainty of a risk estimate results from the superposition of several uncertainty sources. These sources have different relevance for the risk estimate, and therefore, for the decision that has to be made on the basis of the risk analysis. Given this situation, uncertainty analysis helps to identify the weak points of a flood risk analysis. It guides the efforts for assembling further information and data that are supposed to be most valuable for constraining the uncertainty, and therefore, to improve the risk estimate.

This argument is illustrated by means a flood risk analysis for the city of Cologne/Germany (Merz et al., 2002). Flood risk is estimated based on three modules: flood frequency analysis, transformation of flood discharges into river water levels (rating curve), and estimation of direct monetary flood damage for Cologne (damage stage relation), given certain river water levels. The modules describe the flood 


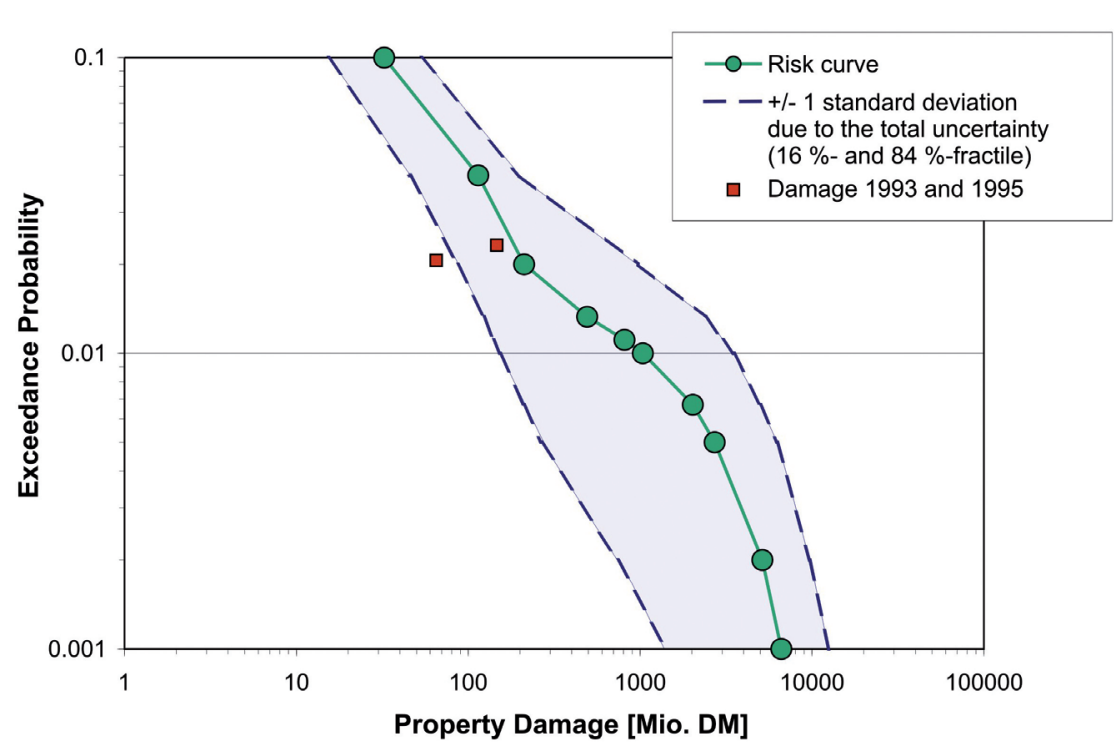

Fig. 1: Flood risk curve for Cologne, including uncertainty bounds (Merz et al., 2002)

processes in a simplified form, allowing for calculation of a very large number of damage scenarios. By means of a second order Monte Carlo simulation, uncertainty bounds are derived for the risk estimates. Figure 1 shows the flood risk curve for Cologne, including an uncertainty band. In a further step, the significance of the uncertainty of the three modules is assessed. Figure 2 gives the (theoretical) reduction of the flood risk uncertainty if a module carried no uncertainty at all, i.e. we provided a perfect module. To derive this figure, the uncertainty calculations were repeated, successively switching off the uncertainty that is attached to each module.

Figure 1 illustrates that the overall uncertainty is significant. Interestingly, the uncertainty bound is widest (at least in the log-diagram) for exceedance probabilities around 0.01 (return period $\mathrm{T}$ of 100 years). This effect is the result of threshold processes linked to the flood defence system of Cologne. Several of the flood defence systems are designed for design floods of around 50 to 100 years. Small uncertainties in the estimations of discharges associated with such return periods can lead to large differences in damage, depending on whether a certain flood defence system fails or not. If it does not fail, there is no damage; if it fails, there may be a significant damage. This threshold effect translates into comparably large uncertainty bounds.

Figure 2 shows that the contribution of the different components of the flood risk analysis to the overall uncertainty varies considerably. Furthermore, the contribution varies with the return period. For small floods (return period $\mathrm{T}<10$ years), the overall uncertainty is dominated by the damage estimation. For larger floods, the flood frequency analysis dominates the overall uncertainty.

In this way, the uncertainty analysis gives additional insight and enhances the risk analysis. It shows that the risk estimate is uncertain which may influence the decisions on flood mitigation. If the uncertainty is deemed too large to be acceptable for a decent decision, the uncertainty analysis helps to prioritize further efforts. In the given case, further work should go into improving the flood frequency estimates for return periods around 100 years.

The separation of risk and un- certainty, as it is shown in figure 1, is only possible if two basic types of uncertainty are distinguished in the risk analysis: aleatory and epistemic uncertainty (e.g., Merz and Thieken, 2005). Aleatory uncertainty stems from variability of the process under study. It refers to quantities that are inherently variable over time, space, or populations of individuals or objects. It exists, for example, in the maximum runoff of a catchment in consecutive years, or in the infiltration capacity across a catchment. Epistemic uncertainty results from incomplete knowledge, i.e. a lack of knowledge about quantities that have fixed but poorly known values. It depends on the ability to understand, measure, and describe the system under study. For example, if we use a mathematical model, epistemic uncertainty may arise in the process of choosing a specific value for the model parameters. The important issue in this context is that epistemic uncertainty can be reduced whereas aleatory uncertainty is not reducible. Merz and Thieken (2005) elaborate on this concept for flood frequency analysis.

Another challenge that flood risk assessments face is the complexity of the models describing the flood processes, especially those of the hydraulic models estimating inundated areas. This results in extensive simulation times and restricts the possibilities of incorporating these models in Monte Carlo based uncertainty analysis, because only a few scenarios can be simulated. The problem increases with the spatial scale of the analysis, for example, if risk assessments are needed for large catchments or extended river reaches. Faced with such situations, risk analysts and modellers prefer to use complex models; an uncertainty analysis is rarely performed. They argue that reliable information about the inundation processes is required in order to get reliable risk assessments. A typical example is the calculation of inundation 


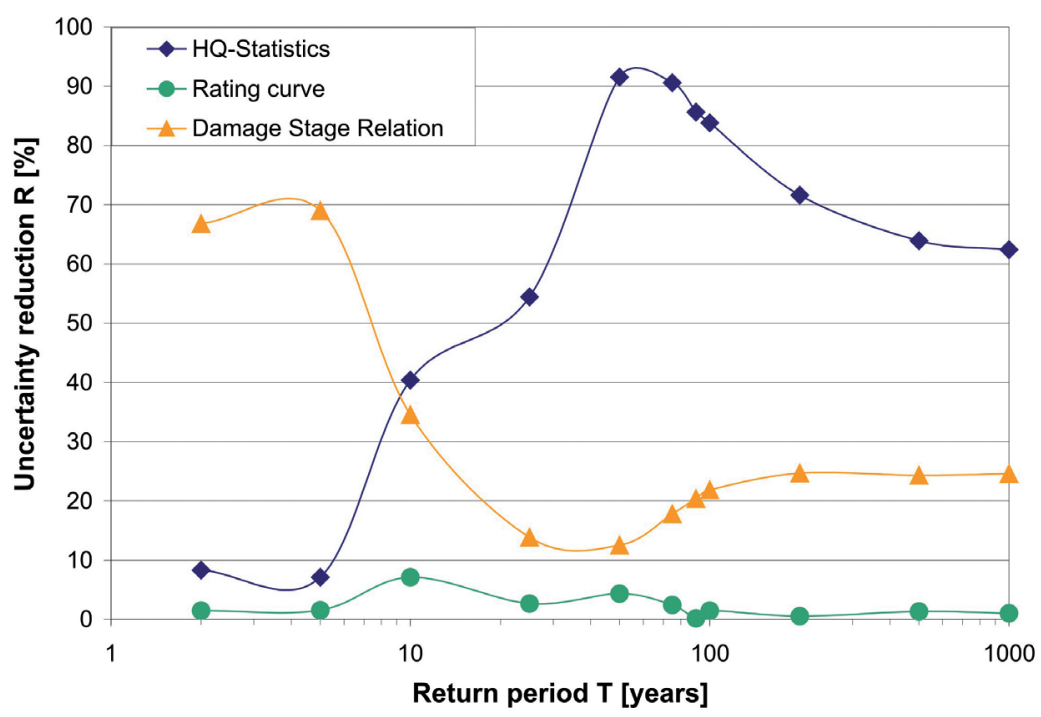

Fig. 2: Uncertainty reduction as indicator for the significance of the different uncertainty sources (Merz et al., 2002)

scenarios including river dike breaching. Complex hydrodynamic simulations are performed, however, just for a very limited number of scenarios. Important aspects of the problem, e.g., location of breach, point in time, width of breach, flood event leading to the breach, are chosen in advance. In our view, this combination of very sophisticated hydrodynamic modelling and negligence of uncertain, however important aspects may not be suitable. In many cases a more appropriate approach is to put more efforts in the investigation of models of reduced complexity, which describe the essential flood processes sufficiently, but with reduced computational demand. The simplified models would be amenable for probabilistic risk assessments and uncertainty analysis. One example of this approach can be found in Apel et al. $(2004,2008)$. The authors developed a flood risk assessment model for complete river reaches protected by dikes. The model includes simplified simulation approaches for flood routing in the channel, dike breaches, and floodplain inundation, amongst others. These models could be embedded in a Monte Carlo framework for both a comprehen- sive flood risk assessment and an uncertainty analysis considering several uncertainty sources. The model produced flood risk estimates for the river reach under study, the Lower Rhine in Germany, and associated uncertainty bands for selected or all considered uncertainty sources (Apel et al., 2008). This simplified system is able to describe the dominant processes and their interaction along the river reach. For example, it facilitates the quantification of the decrease of dike failure probabilities downstream of a dike breach. If a dike breach leads to a significant reduction of the flood peak in the main river, due to large water volumes flowing into the dike hinterland, the dike stretches downstream of the breach location are less prone to breaching.

\section{Uncertainty considerations help to confirm or falsify risk analyses}

Models can be validated, or more correctly phrased (Oreske et al., 1994), confirmed or falsified by the demonstration of agreement between prediction and observation. In hydrological modeling this is usually tantamount to compa- ring observed and simulated time series, e.g., river discharge. The traditional model validation approach, therefore, is based on two assumptions: (1) the system states that are relevant for the purpose of the analysis can be observed, and (2) observations are reliable. These assumptions are mostly fulfilled when the rainfall-runoff behavior of a gauged catchment is simulated. The system states of interest may be repeated many times if a reasonably long time series of observed river discharge is available, and the measurement errors are small.

For flood risk analysis, these assumptions are usually not valid (Hall and Anderson, 2002). The system states of interest, e.g., the 1000-year flood and its associated damages, are rare, and are seldom or not at all contained in the available observations. In some cases the relevant system states cannot be observed since they are unrepeatable. Usually, the failure of a flood defense system is an unrepeatable event. When a failure occurs, people tend to rebuild the defense system with higher safety targets. For example, during the flood in August 2002 more than 130 river dyke breaches occurred in Germany. After the flood, the dyke restoration measures did not restore the situation before the flood - rather, the dykes that were retrofitted are much stronger today than in summer 2002.

Another grave problem is that flood observations, such as river water level, discharge, inundation area and flood damage, are plagued by large measurement errors. The problem of errors in the measurement of flood discharge is well-known among hydrologist. However, they are much less aware of the problematic nature of damage data. The uncertainties associated with damage data is a common problem, since there are no standardized methods or routines to collect and update flood damage data. Depending on the severity of the event and 
on the loss compensation, flood damage is recorded by governmental agencies and insurance companies. Right after a flood event, loss data is collected to provide a basis for decisions about disaster relief assistance (Downton and Pielke, 2005). These data are especially uncertain. For instance, right after the August 2002 flood in Germany, the total flood loss was estimated to be more than 22 billion $€$. This number was corrected to about 9 billion $€$ by December 2002 (BMI, 2002). Final estimates on basis of actual repair costs suggest a total loss of 11.8 billion $€$ (Kron, 2004). Besides, the amount and type of damage collected is dependent on the compensation programs and the amount of available money. For instance, after the August 2002 flood, the German government launched an emergency relief fund of 500 million $€$ and a reconstruction aid fund of 7.1 billion $€$ (Sonderfond Aufbauhilfe). Affected private households and companies could apply for money if the damaged property was located in the catchments of the rivers Elbe or Danube and if the damage had occurred between 10 and 31 August 2002 due to inundation of rivers, dam or dike breaches or high groundwater levels. Damage caused by heavy rainfall or due to business interruption was not reimbursed. All together, governmental assistance amounted to more than $60 \%$ of all losses (Mechler \& Weichselgartner, 2003). In contrast, during the severe flood at the Rhine River in 1993 (total losses of 530 million $€$ ), only $10 \%$ of the losses were compensated by governmental assistance and about $60 \%$ of the losses remained uncompensated (Linneroth-Bayer et al., 2001), i.e. most flood loss data was not recorded in detail. Downton and Pielke (2005) who analyzed historical records of flood damage provided by the National Weather Service (NWS) in the USA reported that damage due to small floods was frequently underestimated or ignored. The collection of damage data is more likely to be systematic and complete in a major flood than in a smaller flood, also since different agencies are more likely to share information about major floods (Downton and Pielke 2005). Loss information from the insurance sector is particularly problematic in countries where insurance coverage is low, which is the case e.g. in Germany or Australia (Blong 2004; Thieken et al., 2006). For example, in Australia small flood losses were not included in the insured losses of the Australian Insurance Disaster Response Organization (Blong, 2004). Another problem was that some loss data could not be allocated to particular events or objects due to a lack of geo-reference and since different data providers used different start and end dates for the same event (Handmer et al., 2005).

Even for a relatively well-documented case, such as the flood situation in Cologne, the available data does not suffice to validate the risk analysis. The last strong floods in 1993 and 1995 have been documented with respect to flood extent and damage (Figure 1). However, it remains unknown how the damage information has been collected and what damage (direct, indirect, economic sectors etc.) is included. Further, the flood risk curve is compared to just two measurement points. Such scarce information gives only a very week hint about the plausibility of the risk analysis. In summary, it follows that flood risk estimates cannot be validated or falsified in the traditional way. Events are very rare or unrepeatable, and observations are missing or erroneous. We can only make judgements on the basis of evidence.

There are several ways towards confirmation or falsification of flood risk analyses:

- Improve process understanding and causal relationships: The poorer the possibilities for directly observing the system states of interest, the more important is the understanding of the processes dominating the system. The processes and their interaction that may lead to extreme floods and to damage have to be understood, and described by adequate causal models (Hall and Anderson, 2002).

- Assemble all kind of evidence: In order to confirm or falsify risk estimates, any information that may help to constrain the uncertainty should be sought for. Different approaches and different sources of information should be used, as much as possible. Faeh et al. (2002) compare flood hazard analysis with a puzzle. All different pieces of information that may help to appraise hazard estimates should be used (flood estimation puzzle). A similar view - "Mehr-Säulen-Ansatz" ("Multi-Column-Approach") - is promoted by Gutknecht (2005).

- Quantify the uncertainty associated with the risk estimate: If the model cannot be validated using observations, all hypothesis testing should explicitly consider the potential sources of uncertainty (Pappenberger \& Beven, 2006). The value of different data types in constraining uncertainty should be assessed. Which assumptions, parameters, data, and relationships are dominating the risk estimate? How reliably can these decisive elements be determined? If the decisive elements are reliable, then the resulting risk estimate is expected to be reliable as well, even if no observations are available. If the decisive elements are contaminated with large uncertainty, then the risk estimate should be used with caution.

This leads to the central question: What is the expected consequence of uncertain elements? Might the uncertainties change the result in such a way that another decision should be taken? 


\section{Uncertainty considerations support decision-making}

The basic assumptions and decisions taken during the course of a risk analysis are hardly presented to the users. Thus, decision makers or the public are rarely aware of the uncertainty and have no chance to assess the uncertainty of the result. Deterministic estimates without an uncertainty range may lead to a loss of credibility and trust in the scientists and the models (if estimate fails) due to the perception of "certain" estimates (Pappenberger \& Beven 2006).

On basis of an uncertainty analysis a decision different, most likely better, than the one taken without the knowledge about the uncertainty is possible. The best estimate e.g. on basis of the mean, is a quite limited information in comparison to an uncertainty statement, e.g. the presentation of a complete distribution function. For instance, if a decision on basis of the benefit-costratio has to be taken between two alternative protection measures, this might be strongly influenced by their uncertainty. Risk-averse decision makers which definitely want to avoid a benefit-cost-ratio below one may prefer the alternative with the smaller uncertainty, although it might have a lower benefit-cost-ratio than the other. Others (risk-neutral) may decide for the alternative with the higher mean benefit-costratio, although the probability that a benefit-cost-ratio below one occurs may be substantial.

Palmer (1999) shows by means of a simple decision-model analysis that probability forecasts of weather and climate have greater potential economic value than single deterministic forecasts. Given a probabilistic forecast, different users with different cost/loss ratios will take precautionary action at different forecast probability thresholds. A user which would suffer a catastrophic loss if a certain event occurred would take precautionary action even when a small probability of the event was forecasted. A user for whom precautionary action was expensive in comparison with any loss would take precautionary action only when a relatively large probability of the event was forecasted.

Analysing two flood management case studies in Colorado, Downton et al. (2005) conclude that uncertainty can have substantial impacts on regulatory processes, public safety and costs. The necessary interpretation of uncertain information, such as flood probabilities, leads to different policies with vast public safety implications. Since different stakeholders of the flood management process have different perspectives, the provision of a single "best" estimate may not necessarily meet the decision needs of all stakeholders (Downton et al., 2005).

A similar issue arises due to the fact that risk analyses often contain value decisions. For example, it may be necessary to decided how ecological damage is taken into account in comparison to economic damage. It is important to clarify the influence of such decisions on the final result. Basically, all relevant assumptions and limitations of a risk assessment should be presented.

Another problem with "best" estimates is that non-linear processes and limits of human imagination may lead to "best" estimates which are not really good (Morgan \& Henrion, 1990). The quality of decisions can be significantly improved due to uncertainty analyses, since the analysis forces one to consider the whole range of possible outcomes. The focus should be upon critical uncertainties that may change the ordering between decision options (Hall et al., 2006). Some decisions do not need full explicit quantification of uncertainties, e.g. because the best risk management strategy is fairly obvious.

It may be important for decision making to appreciate the degree of disagreement among experts about different hypotheses and its effect on the results (Pate-Cornell, 1996). An uncertainty analysis helps to clarify what is known and what is not. In situations with very large social and political uncertainty, pluralism has been frequently recommended. Diverse policy approaches or measures should be adopted to increase the likelihood that at least some of these will prove useful (Shackley et al., 1998). Additionally, in situations where only very uncertain statements can be made, provisions have to be made for the case that the analysis underestimates the flood risk. Such a situation is discussed by Zerger et al. (2002). The analysis of the storm surge risk of Cairns, Australia, showed that due to small topographic gradients small errors in the digital elevation model may lead to large differences in the predicted inundation areas. In such a case, it is not sufficient to indicate flooded and non-flooded, i.e. safe, areas for a certain storm surge. It is necessary to prepare evacuations for the case that predictions are wrong and underestimate unsafe areas.

It is often argued that policy makers and the public are not able to understand concepts of uncertainty nor probability. Risk models that show spatial uncertainty may be too complex for interpretation by untrained individuals and may be ignored or misinterpreted (Zerger et al., 2002). Certainly it is a challenge to communicate probabilistic information so that it will be used appropriately. Important for the communication of uncertainties is the target audience (Patt \& Dessai 2005). Effective communication should eliminate biases and allow the decision-makers themselves to arrive at wise judgments (Patt \& Dessai 2005). Positive examples are probabilistic weather forecasts which are accepted nowadays. 


\section{Conclusions}

In our opinion, flood risk analyses should be accompanied by an estimate of the uncertainty of the risk statement. We support this view by examining the value of uncertainty analysis for improving and validating risk estimates, and for decision-making. Uncertainty analysis improves flood risk analysis since it forces the risk analyst to scrutinize assumptions, models and data underlying the risk analysis. It helps to identify the weak points of a risk analysis, and maybe most importantly, it helps to prioritise further information in order to constrain the uncertainty. Further, flood risk analysis cannot be validated in the traditional way, since the necessary observations are lacking. We can only make judgements on the basis of evidence. In this situation uncertainty analysis is a means to support the plausibility of the risk estimate. If the decisive elements of the risk analysis are reliable, then the resulting risk estimate should be reliable as well. Otherwise, the result of the risk analysis should be used with caution. Finally, the value of uncertainty analysis for decision-making is discussed. There are many examples and theoretical considerations that uncertainty analysis may improve decision-making. People are used to take decisions under large uncertainty. Information about the uncertain- ty of the risk estimate may help to choose among the different flood mitigation options, for example, by allowing the decision-maker to consider his attitude concerning risk aversion. Last but not least, it is an ethical obligation to provide the decision-maker with an idea of the reliability of the risk analysis. In situations with large uncertainty, provisions can be made for the case that the risk is wrongly quantified.

\section{Correspondence:}

GeoForschungsZentrum Potsdam

Telegrafenberg

14473 Potsdam, Germany

bmerz@gfz-potsdam.de

\section{REFERENCES}

Apel, H., Thieken, A., Merz, B., Blöschl, G. (2004) Flood risk assessment and associated uncertainty, $\mathrm{Na}$ ural Hazards and Earth System Sciences, 4, 295-308. Apel, H., Thieken, A., Merz, B., Blöschl, G., 2006: probabilistic modeling system for assessing flood risks. Natural Hazards, 38(1-2), 79-100.

Apel, H., Merz, B., Thieken, A.H. (2008): Quantification of uncertainties in flood risk assessments, Journal of River Basin Management, accepted for publication. Blong, R. (2004): Residential building damage and natural perils: Australian examples and issues, Building Research \& Information, 32, 379-390.

BMI (Bundesministerium des Innern) (2002): Bundesregierung zieht vorläufige Schadensbilanz der Hochwasserkatastrophe: bisher finanzielle Hilfe im Umfang von über 700 Millionen Euro geleistet (Federal government draws provisional damage balance of the llood disaster: hitherto financial assistance provided to the extent of over 700 million EUR), Press release (6 November 2002), www.bmi.bund.de/dokumente/Pressemitteilung/ix90912.htm.

Downton, M. W., Pielke Jr., R.A. (2005): How accurate are Disaster Loss Data? The Case of U.S. Flood Damage, Natural Hazards, 35, 211-228.

Downton, M.W., Morss, R.E., Wilhelmi, O.V., Gruntfest, E. Higgings, M.L. (2005): Interactions between scientific e., Higgings, M.L. (2005): Intertion Two cas in 6, 134-146.

, Herath S, Musiake K. (2003): A mathematimodel for flood loss estimation, Journal of Hydrology, 277(1-2), 24-49.

Faeh, A., Cavelti, B., Zarn, B., Müller-Lemans, H. (2002): The flood estimation puzzle. In: Intern. Commission for the Hydrology of the Rhine basin, Proc.
Intern. Conf. on Flood. Estimation, 6-8 March, 2002, Berne, CHR-Report II-17, 469-478.

Gutknecht, D. (2005): Risikomanagement extremer Gutknecht, D. (2005): Risikomanagement extremer Hochwasserereignisse, Invited lecture, Kick Off meeting RIMAX, GFZ Potsdam (www.rimax-hochwasser.de/459.
html).

Hall, J.W. (2003): Handling uncertainty in the hydroinformatic process, Journal of Hydroinformatics, 05.4 215-232.

Hall, J., O'Connell, E., Ewen, J. (2006): On not un dermining the science: coherence, validation and expertise. Discussion of Invited Commentary by Keith Beven, Hydrological Processes, 20, 3141-3146.

Handmer, J., Abrahams, J., Betts, R., Dawson, M. (2005): Towards a consistent approach to disaster loss assessment across Australia, The Australian Journal of Emergency Management, 20, 10-18.

Kron, W. (2004): Zunehmende Überschwemmungsschäden: Eine Gefahr für die Versicherungswirtschaft? (Increasing flood damage: a hazard for the insurance industry?), ATV-DVWK: Bundestagung 15-16 September 2004 in Würzburg, DCM, Meckenheim, 47-63.

Linneroth-Bayer, J., Quijano-Evans, S., Löfstedt, R. Elahi, S. (2001): The uninsured elements of natural catastrophic losses, Final report submitted in fulfillment of grant from Tsunami fund UK, IIASA, Lan Mecher, P. Weich Mechler, R., Weichselgartner, J. (2003): Disaste The Elbe River burg.

Merz, B., Thieken, A., Blöschl, G. (2002): Uncertain Merz, B., Thieken, A., Blöschl, G. (2002): Uncertain
ty analysis for flood risk estimation, Intern. Commission for the Hydrology of the Rhine basin, Proc. Intern. Conf. on Flood Estimation, 6-8 March 2002, Berne, CHR Report II-17, 577-585.
Merz, B., Kreibich, H., Thieken, A., Schmidtke, R. (2004): Estimation uncertainty of direct monetary flood damage to buildings, Natural Hazards and Earth System Sciences, 4, 153-163.

Merz, B., Thieken, A. (2005): Separating natural and Merz, B., Thieken, A. (2005): Separating natural and
epistemic uncertainty in flood frequency analysis, Journal of Hydrology, 309(1-4), 114-132.

Mor Morgan, M.G., Henrion, M. (1990): Uncertainty: guide to dealing with uncertainty in quantitative risk and policy analysis, Cambridge University Press, Cambridge, UK, $332 \mathrm{pp}$

Oreske, N., Shrader-Frechette, K., Belitz, K. (1994): Verification, validation and confirmation of numerical models in the earth sciences, Science, 263, 641-646.

Pappenberger, F., Beven, K. (2006): Ignorance is bliss. Or seven reasons not to use uncertainty analysis, Water Resources Research, 42, W05302, doi:10.1029/ 2005WR004820.

Pate-Cornell, E. (1996): Uncertainty in risk analysis: Six levels of treatment, Reliability Engineering and System Safety, 54, 95-111.

Shackley, S., Young, P., Parkinson, S., Wyne, B. (1998): Uncertainty, complexity and concepts of good science in climate change modelling: Are CGMs the best tools? Climate Change, $38,159-205$.

Thieken, A., Petrow, T., Kreibich, H., Merz, B. (2006) Insurability and mitigation of flood losses in private Insurabitity and mitgation of hlood losses in private Zerger, A, Smith, D. Hunter, G. Jen, S.D. Zerger, A., Smith, D.I., Hunter, G.J., Jones, S.D. (2002): Riding the storm. A comparison of uncertainty Applied Geograph, $22,307-330$. 